This paper presents a general idea of the historical relations between art education and visual culture education; and it briefly describes the situation of contemporary art education in relation to issues of gender, sexuality, curriculum, censorship and morality. It is based on the premise that art education, by developing new practices, ways of knowing, epistemologies, identities, subjectivities, agencies and acceptance of the everyday life, is passing through a radical change and moving towards the visual culture education. It suggests that the inclusiveness of the visual culture education is able to give visibility and effectively assist understanding representations of gender and sexuality in society.

Keywords: visual culture education, art education, gender/sexuality. 


\section{Acoitamentos: \\ os locais da sexualidade e gênero na arte/educação contemporânea'}

Belidson

DIAS

O trabalho apresenta uma visão panorâmica das relações históricas entre a arte/educação e a educação da cultura visual e descreve, sucintamente, a situação da arte/educação contemporânea em relação às questões de gênero, sexualidade, currículo, censura e moralidade. Baseia-se na premissa de que a arte/educação passa por uma mudança radical em direção à educação da cultura visual ao desenvolver novas práticas, epistemologias, identidades, subjetividades, agências e entendimentos do cotidiano. Sugere que a inclusão da educação da cultura visual pode dar visibilidade e efetivamente auxiliar a compreensão das representações visuais de gêneros e sexualidades na sociedade.

Palavras-chaves: educação da cultura visual, arte/educação, gênero/sexualidade. 
As práticas cotidianas da arte/educação contemporânea no Ensino Fundamental², Médio e Superior, no Brasil, são marcadas pela negligência com a experiência cultural do cinema, o descaso com questões de gênero, assim como a ocultação e dissimulação do assunto "sexualidade". Todavia, este não é um privilégio nosso. Situação semelhante existe seguramente nos Estados Unidos, Canadá e Reino Unido e, possivelmente, em outros países europeus e latino americanos, embora a situação seja um pouco melhor no Ensino Superior, principalmente nos estudos visuais, artes visuais, cinema, audiovisual, publicidade e comunicação visual. Nos programas de formação de professores, ou seja, nas licenciaturas em artes visuais/plásticas, não existe o debate dessas questões para a construção de novas experiências curriculares em arte/educação.

As questões da visualidade, representação de gênero e sexualidade são centrais nos debates da nossa vida diária. Assim, uma vez que nós vivemos em um mundo tecnológico multifacetado onde as imagens são um produto essencial, uma commodity, para nossa informação e conhecimento (DEBORD, 1995), então é vital para a educação que estudantes e educadores conscientizem-se das maneiras e razões pela quais são atraídos por um imaginário visual do cotidiano (DUNCUM, 2002a). É evidente que desenvolver novas abordagens analíticas sobre os modos de ver é, atualmente, uma ação importante e um desafio crucial para a maioria das disciplinas acadêmicas, mas, incontestavelmente, é um assunto essencial para a arte/educação contemporânea.

É sobre essas questões, pois, que me volto neste texto. Inicialmente, apresento uma visão panorâmica das relações históricas entre a arte/educação e a educação da cultura visual. Em seguida, descrevo, sucintamente, a situação da arte/educação contemporânea em relação às questões de gênero, sexualidade, currículo, censura e moralidade.

No entanto, quero lembrar ao leitor sobre o uso de certas nomenclaturas neste texto. Aqui "arte/educação" é entendida como qualquer prática de ensino e aprendizagem em artes visuais, em qualquer relação de tempo e espaço. Já "arte/educação contemporânea" é entendida somente como as práticas corren- 
tes, recentes, em ensino e aprendizagem de artes visuais, isto é, as práticas que ainda estão sob suspeita, suspensão, investigação, experimentação e que não se fixaram. Além disso, nesse contexto, o termo não é sinônimo de Nova Arte Educação, Arte Educação Pós-moderna, Arte Educação Reconstrucionista, ou Arte Educação Multicultural, embora ele possa compreender todas essas tendências. Ainda mais, neste texto, "educação da cultura visual" significa a recente concepção pedagógica que destaca as ubíquas representações visuais do cotidiano como os elementos centrais que estimulam práticas de produção, apreciação e crítica de artes e que desenvolvem cognição, imaginação, consciência social e sentimento de justiça.

\section{Os encontros entre Arte/Educação e Educação da Cultura Visual}

Embora o campo da Educação, dos anos Noventa até agora, viu o aparecimento de trabalhos que examinam eficientemente aspectos do ensino e da cultura visual, somente agora, tão recentemente quanto 2002, foi que pude encontrar uma literatura consistente que trate da interseção do ensino de arte e cultura visual (EMME, 2001; FREEDMAN, 2001; CHALMERS, 2002; DUNCUM, 2002b; BOLIN e BLANDY, 2003; CHAPMAN, 2003; FREEDMAN, 2003; KINDLER, 2003; PAULY, 2003; SULLIVAN, 2003; TAVIN, 2003; DUNCUM, 2004).

A cultura visual, como um campo emergente de pesquisa transdisciplinar e trans-metodológico, que estuda a construção social da experiência visual, é ainda extraordinariamente fluido, um conceito mutável sujeito a múltiplos conflitos. Entretanto, apesar das disputas em torno dele, há uma compreensão que a cultura visual enfatiza: as experiências diárias do visual e move, assim, sua atenção das Belas Artes, ou cultura de elite, para a visualização do cotidiano. Além disso, ao negar limites entre arte de elite e formas de artes populares, a cultura visual faz do seu objeto de interesse todos os artefatos, tecnologias e instituições da representação visual. Representação visual concebida, aqui, como um local onde a produção e a circulação 
dos sentidos ocorrem e são constitutivas de eventos sociais e históricos, não simplesmente uma reflexão deles (HALL, 1997). Nesse entendimento, o ensino e a aprendizagem da cultura visual, a educação da cultura visual, não suprime as artes de elite do currículo. Em suma, a educação da cultura visual, de acordo com essa visão, aborda os percursos curriculares a partir de perspectivas inclusivas nas quais diferentes formas de produção da cultura visual possam ser estudadas e entendidas de um modo mais relacional e contextual e menos hierárquicas.

A educação da cultura visual situa questões, institui problemas e visualiza possibilidades para a educação em geral, características que não encontramos destacadas atualmente em nenhum outro lugar do currículo em arte/educação. Isto ocorre porque ela conduz os sujeitos à consciência crítica e a crítica social como um diálogo preliminar, que conduz à compreensão, e, então, à ação. Nessa análise, a melhor palavra para descrever este processo é "agência": uma consciência crítica que conduz a ações assentadas para resistir a processos de superioridades, hegemonias e dominação nas nossas vidas diárias. Nessa direção, a educação da cultura visual é aberta a novas e diversas formas de conhecimentos, promove o entendimento de meios de opressão dissimulada, rejeita a cultura do Positivismo, aceita a idéia de que os fatos e os valores são indivisíveis e, sobretudo, admite que o conhecimento é socialmente construído e relacionado intrinsecamente ao poder. Necessariamente, a educação da cultura visual incentiva consumidores passivos a tornarem-se produtores ativos da cultura, revelando e resistindo no processo às estruturas hegemônicas dos regimes discursivos da visualidade.

Este foco da cultura visual, em uma noção mais ampla do que é o visual e visualidade, parece ser um dos elementos chave para se compreender a hesitação de muitos arte/educadores em engajar-se à cultura visual. Historicamente, os currículos de arte foram implementados na educação fundamentados nos valores da elite cultural, com um grande débito aos princípios do desenho/design. Assim, o formalismo, que está incrustado nos princípios do design e um forte constituinte do Modernismo, transformou-se numa das posições preferidas do campo (DUNCUM, 
1990; EFLAND, 1990; BARBOSA, 1991; HOBBS, 1993; BARBOSA, 2001). O Modernismo assumiu o conceito de um objeto de arte independente e da existência objetiva de valores estéticos inerentes às propriedades formais do objeto da arte. Portanto, enfatizava que os objetos da arte poderiam existir sozinhos e, assim sendo, os valores e as experiências estéticas seriam verificáveis. Logo, o Modernismo separou o espectador e o autor deste objeto autônomo chamado "arte". Dessa forma, as Belas Artes passaram a ser avaliadas pela sua própria razão e oportunos critérios, e todas as formas restantes de representação visual da sociedade que tivesssem função "utilitária", ou seja, a princípio um uso não-estético, foram diminuídas de valor.

Contudo, as coisas mudam e, de acordo com Kuhn (1970), paradigmas mudam de maneiras desordenadas. Longe das lógicas dialéticas puristas da perspectiva historiográfica das teorias modernistas, é preciso reafirmar que os paradigmas não são monolíticos, nem homogêneos com respeito ao tempo e espaço. Eles experimentam mudanças radicais.

Nesse contexto, eu entre outros arte/educadores, consideramos que a arte/educação contemporânea passa por uma mudança radical de suas práticas ao contemplar abertamente aspectos da cultura visual no currículo, desenvolvendo novas práticas que provocam o deslocamento de noções rígidas de recepção/produção de imagens, epistemologia, poder, identidade, subjetividade, agência e entendimento do cotidiano. Além disso, de uma forma ou de outra, atualmente, as escolas de arte e cursos de licenciatura em arte/educação têm que enfrentar a necessidade social de desafiar as noções predominantemente formalistas dos seus currículos e começar a explorar intensamente as experiências do cotidiano, dos sujeitos, suas trocas materiais e sensoriais. É, pois, dessa perspectiva que os arte/educadores são chamados a discutir e entender porque, historicamente, o currículo de arte/educação em geral tem valorizado, sobretudo, a produção e apreciação artística das Belas Artes, em vez de buscar a compreensão crítica da representação da visualidade na sociedade.

Durante os últimos quinze anos, preponderantemente na América do Norte, surgiram alguns esforços em discutir, pro- 
mover e implementar o que foi descrito como a Nova Arte-Educação, ou Ensino Contemporâneo de Arte, ou até mesmo a Arte Educação Pós-Moderna, que por sua vez são conceitos identificados na maior parte com os princípios da Disciplined-Based Art Education (DBAE) e do Ensino Multicultural de Artes. O DBAE é uma estrutura conceitual, um projeto filosófico e metodológico que busca assegurar a todos os estudantes um estudo rigoroso e disciplinar das artes visuais como parte da sua educação formal universal. Seu princípio norteador é que os estudantes façam artes, localizem os contextos históricos e culturais, os valores e os conceitos das artes e, igualmente, façam julgamentos sobre elas. Já a Educação Multicultural de Artes busca promover, por meio da consciência cultural da arte, oportunidades iguais para aprender e promover a identidade individual e social. Já os arte/educadores multiculturalistas afirmam que os temas que se relacionam à diversidade na sociedade, cultura e identidade estão incorporados nas práticas artísticas. Assim, a arte deve ser vista como um local privilegiado para a aprendizagem de estudos sociais e também deve ser utilizada para ampliar o conhecimento de assuntos, como o etnocentrismo, estereótipos de representação, a discriminação, o racismo, entre outros.

Desde então, indubitavelmente, ocorreram algumas mudanças e os programas de arte/educação se comprometeram em explorar os diversos meios, além dos tradicionais: pintura, escultura, cerâmica, gravura, desenho e tecelagem. Também estão lentamente incorporando aspectos dos estudos culturais, da cultura visual e da crítica e apreciação da arte em suas práticas. Durante o início dos anos Noventa, o campo da arte/ educação começou a perceber a relevância da cultura visual como material pedagógico e objeto curricular. A despeito das frustradas tentativas iniciais, aproximadamente entre os anos Cinqüenta aos Noventa, de arte/educadores em enlaçar a onipresente cultura visual, foi somente na metade dos anos Noventa que os discursos sobre a cultura visual surgem vigorosos nos escritos de alguns poucos, mas influentes pesquisadores do campo (DUNCUM, 1987a; DUNCUM, 1987b; BOLIN, 1992; FREEDMAN, 1994; DUNCUM, 1997; FREEDMAN, 1997). 
Entretanto, Chalmers (2005) observa que esse recente aparecimento da cultura visual no currículo está sujeito às experiências e teorias que aconteceram e foram produzidas antes, pois, para ele os anos Sessenta foram os mais significativos para a fundação do que veio a se desenvolver ultimamente como a educação da cultura visual. No mesmo artigo, Chalmers informa que a tentativa mais consistente de introduzir a cultura visual no currículo de arte/educação aconteceu por meio de trabalhos seminais de Corita Kent, Vincent Lanier e, particularmente, de June King McFee, que abasteceram o campo com conceitos e idéias sustentáveis sobre a cultura visual, cujos efeitos são sentidos nas práticas da arte/educação até hoje. Ao olhar para a arte como uma possibilidade de estudo do social, preocupando-se com a compreensão das possibilidades de ensinar, desenvolver métodos e de justificativas para o estudo da cultura visual, McFee antecipou a educação da cultura visual contemporânea, afirma Chalmers (2005, p. 10). Entretanto, ele observa que os arte/educadores, naquele tempo, não perceberam imediatamente as possibilidades e instrumentalidades pedagógicas para o campo e, assim, não desenvolveram agência "porque eles [Kent, Lanier e MacFee] falharam em reconhecer que, apesar da cultura da juventude dos anos Sessenta, a maioria daqueles que estavam ensinando nas escolas fizeram a sua formação em educação nos relativamente conservadores anos Quarenta e Cinqüenta" (2005, p. 6). Além disso, Chalmers lembra-nos que o estudo da cultura visual, naquele período, criou oportunidades para começar a desconstruir as hierarquias entre Belas Artes e cultura popular, e que foram seminais para os desenvolvimentos teóricos da Nova História da Arte e, posteriormente, da materialização da educação da cultura visual. De acordo com Chalmers, o campo encontra-se hoje mais preparado para aceitar e lidar com a cultura visual.

Paul Duncum (2002a) afirma que progressivamente um maior número de arte/educadores estão usando o termo "cultura visual" em vez de "arte"; e não obstante os seus vagos conceitos do que é e a importância da cultura visual, eles vêm reconhecendo que a distância entre os conceitos modernistas de arte de elite e arte popular vêm se retraindo. Parece evidente 
para Duncum que a cultura visual não está somente interessada em lidar com o visual, mas ao contrário, com todas as outras formas de comunicação sensorial. Novamente, Duncum (2002a) observa que o fenômeno social da visualidade abriga interações entre todos os sentidos e, desse modo, a cultura visual pode dirigir sua atenção não somente aos fatos e artefatos visuais observáveis, mas também a diferentes maneiras e contextos diversos da visão, da representação visual e suas mediações. Nesse entendimento, Duncum reafirma que alguns aspectos da visualidade, que se refere a como nós olhamos, vemos, contemplamos, fitamos, miramos, observamos, testemunhamos, examinamos, vislumbramos, olhamos de relance, espiamos, espreitamos e entrevemos o mundo, é particularmente relevante para a construção da representação do conhecimento. Revela uma necessidade para uma exploração adicional dos conceitos da comunicação e representação cultural da visualidade.

Freedman (2003) expande esse caso apresentado por Duncum, ainda mais, ao promover o ensino da cultura visual, atribuindo atenção especial à visão, à interpretação e à construção de sentidos por meio de imagens. Freedman escreve:

A diferença entre os contextos da produção e os contextos da visão é crítica e pode influenciar a aprendizagem dos estudantes. As artes de culturas tradicionais, geralmente, são recontextualizadas quando apreciadas em contextos contemporâneos. No entanto, as diferenças entre contextos de fazer e de ver não são dados geralmente a atenção merecida no currículo. As imagens, hoje em dia, freqüentemente são vistas sem apresentar o contexto de sua intenção original e, geralmente, apresentam-se justapostas a imaginários previamente desconectados do contexto original, o que provocam novas associações de sentidos para este novo contexto. (2003, p. 90)

Nessas proposições de Freedman, fundamenta-se uma importante abordagem pedagógica que chama a atenção para o "ver" e o "fazer" dentro dos currículos de arte/educação, e que analisa criticamente a cultura visual, destaca as características cognitivas das interações contíguas entre aqueles que vêem e aquilo que é visto, e ainda explora a questão de como é que nós construímos imagens ao mesmo tempo em que elas nos 
constroem. Duncum e Freedman trazem à tona a necessidade de reconhecer diversos contextos e contigüidades da visão, produção e representação e, neste processo, a arte/educação transforma-se num instrumento de pedagogia crítica em que as intenções, finalidades, interpretações, influências e o poder de representações visuais provocam um reconstrucionismo social crítico, uma pujante educação da cultura visual.

Neste momento, cabe um esclarecimento. Em um sentido pragmático, eu somente uso o termo "educação da cultura visual" denotando uma pedagogia crítica que não sugira, nem promova uma metodologia ou pedagogia unificada e específica, ou ainda, que indique um currículo exclusivo. Ao contrário, a educação da cultura visual é mais bem entendida, aqui, como um projeto do que como um método e constitui-se num grupo flexível de conceitos transdisciplinares para promover, entre outras coisas, a identidade individual e a justiça social na educação. Inegavelmente, por meio da intertextualidade e da "intergraficalidade", conceito que Freedman (2003, p. 121) cunhou para mostrar que imagens e artefatos existem num processo intenso de trocas de contextos e sentidos, a educação da cultura visual importuna hierarquias conceituais e, ao mesmo tempo, integra a visualidade do cotidiano ao currículo. Conseqüentemente, a educação da cultura visual acontece como uma compreensão dos processos cognitivos entre aqueles que produzem e os que apreciam a visualidade da vida diária e, desse modo, nos convida a ponderar sobre o imaginário social como se fosse uma instalação de assuntos sociais que afetam noções, conceitos, opiniões, valores e apreciações da arte. O resultado é que o estudo crítico da representação visual na cultura do cotidiano é capaz de engajar a arte/educação em uma práxis de justiça social.

Mas, vários arte/educadores não vêem e entendem a cultura visual e a educação da cultura visual, como apresentei anteriormente. Eles afirmam que o deslocamento do foco de interesse de ensinar e aprender as Belas Artes para privilegiar a cultura visual substitui o estudo da "arte" pelo dos estudos sociais. Há, pois, importantes perguntas que surgem dessas divergências: 
- Os estudantes deveriam ser expostos à cultura visual? Por que não?

- Os estudantes devem ser expostos somente às Belas Artes? Por quê?

- As obras de arte tradicionais das Belas Artes devem ser estudadas como parte do estudo da cultura visual?

Alguns arte/educadores contestam as atividades, práticas e esforços da educação da cultura visual de desejar "salvar" a arte/educação como uma disciplina, temendo que ela substitua os seus atuais objetivos, projetos e finalidades (SMITH, 1988; SMITH, 1992b; 1992a; SMITH, 2003; HEISE, 2004; SILVERS, 2004; VAN CAMP, 2004).

Hoje em dia, os arte/educadores que disseminam mais abertamente suas ressalvas sobre a educação da cultura visual são Torres e Kamhi, os editores da Aristos: An online Review of the Arts (TORRES, 1991; KAMHI, 2002; KAMHI, 2003, 2004; TORRES, 2004; KAMHI, 2005; TORRES, 2005a; 2005b). Ambos os pesquisadores discutem que a educação da cultura visual não tem nenhum lugar na arte/educação porque não articulam claramente uma compreensão de que arte "realmente é". Contudo, eles também não nos esclarecem sobre o "verdadeiro" conceito de arte a ser seguido pelos arte/educadores. Continuando, Torres e Kamhi asseveram que a cultura visual trata a arte como se ela não tivesse nenhuma natureza ou valor distintivo, e que os seus teóricos reduziram o conceito de arte ao de artefato cultural. Mais ainda, nos artigos citados acima, eles argumentam que os estudos da cultura visual engolfaram completamente a arte/educação porque o seu objeto de estudo, a cultura visual, se "extrai" do contexto geral da cultura, mas ao fazê-lo, ignora as "qualidades essenciais" das Belas Artes. Por outro lado, os autores desviam-se da responsabilidade de descrever quais são as qualidades essenciais da arte e do objeto estético. Torres e Khami ainda insistem que a educação da cultura visual negligencia diferenças essenciais entre trabalhos de Belas Artes e outros tipos de artefatos culturais, e valorizam questões sociais e políticas à custa de experiências pessoais mais concretas produzidas pelas Belas 
Artes. Além disso, eloqüentemente, afirmam que a abordagem da educação da cultura visual quanto à compreensão da interpretação de imagens, extenua os assuntos políticos que dividem a sociedade, tais como raça, classe, sexualidade, gênero e etnicidade.

De um ponto de vista mais crítico, Aguirre (2004) inicialmente afirma que a educação da cultura visual degrada o fazer artístico ao privilegiar apenas a análise e a compreensão da arte. Depois, ele assegura que, por desafiar a univocalidade da arte à educação da cultura visual, coage arte/educadores a negligenciar a perspectiva de estudo baseada na estética para poder posicioná-la "exclusivamente" dentro do campo dos Estudos Culturais.

Além destes, muitos outros arte/educadores alegam que não estão preparados para tratar da complexidade dos locais da cultura contemporânea e de suas práticas interdisciplinares, multidisciplinares ou transdisciplinares, porque não foram previamente treinados para tais atividades (apud DUNCUM, 2002a). Contudo, eu me indago se estes mesmos arte/educadores sentem-se inteiramente preparados para dar aulas de teoria, história e crítica da arte, fundamentos da linguagem visual, estética e fazer artístico, como tem sido exigido pelo DBAE ou a metodologia triangular, no Brasil. Sobretudo porque, para trabalhar com esses tipos de estruturas curriculares, eles também necessitam de uma abordagem interdisciplinar. Mas, o que tem de tão errado nos Estudos Culturais? Que tipo de arte/educadores somos nós que podemos ser violentados por uma proposição pedagógica? Os Estudos Culturais formam um campo transdisciplinar, não admitem exclusividades disciplinares e promovem o trânsito de conhecimento sobre comunicação, cultura e poder. Portanto, esse possível destronamento do estético é uma ingênua projeção do medo que arte/educadores desenvolveram ao se aproximarem da idéia de cultura/arte como um conjunto de práticas, contrariamente ao estabelecido entendimento de que cultura/arte é um conjunto de obras. Mas, como vimos anteriormente, o objeto estético não perde o seu poder na cultura visual. Ele, simplesmente, é investido de outros poderes que o relacionam ao seu contexto social. 
Outros arte/educadores, como Bauerlein (2004), radicalmente discutem que este movimento em direção à cultura visual é uma invasão, uma contaminação, que virá e partirá de forma sazonal, porque ele é baseado em práticas e características enganadoras, promíscuas, limitadas e arrogantes, tais como o uso extensivo das intertextualidades, a flexibilidade em utilizar várias disciplinas sem conhecê-las em profundidade, e o uso descomedido da cultura visual como objeto estético. Mesmo aqueles que apóiam a educação da cultura visual, reconhecem a necessidade de mais estudos para a área. Desai (2005) assente que é na tradução de conceitos da cultura visual em salas de aula de artes que se encontra o desafio para a implementação da educação da cultura visual. Do mesmo modo, Freedman, uma defensora crítica da educação da cultura visual, propõe mais estudos e pesquisas em torno das características didáticas da cultura visual, liderança e currículos, mudança institucional, e conexões entre a teoria e novas políticas públicas e privadas.

Algo similar ocorreu quando Stankiewicz, a ex-presidente da National Art Education Association (NAEA), apresentou o planejamento estratégico da instituição na conferência anual de 2003 (STANKIEWICZ, 2004). O objetivo preliminar do plano era valorizar as pedagogias que incentivassem a aprendizagem das artes visuais por meio de uma grande variedade de visões, proposições, funções, princípios, fontes e procedimentos. Stankiewicz, partindo das idéias de Eisner (2002) sobre as visões e versões da arte/educação contemporânea, admitiu que há muitas formas de se fazer arte/educação, e que estas versões distintas operam simultaneamente e até justapõem-se em muitas práticas. Mais ainda: que os arte/educadores devem estar livres para escolher uma ou mais abordagens existentes, tais como o DBAE, a educação da cultura visual, a resolução de problemas, a arte/educação como preparação para o mundo do trabalho, as artes e o desenvolvimento cognitivo, ou as artes para promover o desempenho acadêmico.

Entretanto, neste momento, é importante levantar algumas questões, dividir inquietações e esclarecer algumas coisas. Por mais que eu concorde que os arte/educadores devam imple- 
mentar várias práticas pedagógicas e escolher diferentes abordagens baseadas em seus contextos pessoais e sociais, é importante lembrar, entretanto, que o projeto da educação da cultura visual não se opõe à arte/educação, nem tampouco é uma seção da arte/educação, como apresentada por Eisner (2002). Pelo contrário, a educação da cultura visual é inclusiva de todas as formas de relações de ensino e aprendizagem da visualidade e seus produtos culturais. Portanto, para além das "visões" de Eisner (1976; 2002), eu estou convencido de que a cultura visual não é apenas um elemento adjacente a algumas de suas visões para a arte/educação, mas sim um elemento chave para desconstruí-la e, a partir daí, construir, reconstruir, e constituir a educação da cultura visual.

Um outro problema que encontro constantemente com a maioria das críticas e teorias contrárias à educação da cultura visual está ao alegar que a ela falta rigor científico, metodologia, estabilidade e eficiência. É o modo acrítico de refletir somente por oposições binárias, que por sua vez sustentam este questionamento. Por isso, ao buscar um deslocamento dessa norma, reafirmo que a "arte" não se opõe à cultura visual, nem aos estudos sociais. Ela ocupa posições trans-relacionais entre elas. Logo, a educação da cultura visual pode ser entendida também como um deslocamento de paradigma de uma arte/ educação de tendência Modernista para uma prática pedagógica que não envolve a dialética da oposição binária.

Para estabelecer o seu valor como campo de estudo, a arte/ educação foca em determinados objetivos e em certas formas de conhecimento, usando diferentes meios e métodos para atingir estes alvos e adquirir conhecimentos, estabelecendo, assim, um paradigma. Afinal, o paradigma é, essencialmente, a afluência de entendimentos, opiniões, valores, experiências, métodos e conhecimentos compartilhados por estudiosos e praticantes de um campo, que por sua vez deliberam acordos sobre como as teorias e os problemas do campo devem ser abordados. Quando os modelos ou os paradigmas dominantes aproximam-se de um esgotamento, eles não conseguem mais se explicar, nem considerar adequadamente os fatos observados no campo. Então, os deslocamentos de paradigmas ocorrem e, geralmente, 
são pontuados por posições intelectuais radicais em que uma perspectiva conceitual substitui a outra. Mas, como sabemos, os deslocamentos paradigmáticos não ocorrem a toda a hora: são extremamente raros, levam um longo tempo para ocorrer e, ainda mais, para serem reconhecidos (KUHN, 1970).

Por conseguinte, o que nós temos ouvido ultimamente no campo da arte/educação, como o aparecimento da educação da cultura visual, é somente o estampido de vozes dissidentes desses influentes estudiosos que não entendem como as abordagens, práticas e perspectivas atuais da arte/educação podem se aproximar dos contextos dos indivíduos e da sociedade contemporânea. Conseqüentemente, estes estudiosos têm-se encontrado, coletado informações, discutido, debatido e dialogado para promover este deslocamento paradigmático radical. Está além do escopo deste texto demonstrar como este deslocamento tem ocorrido exatamente, mas certamente, ele não começou nestas últimas décadas, mas sim há um longo tempo atrás por meio do trabalho de estudiosos de vários campos do conhecimento e provenientes de várias partes do globo. Levou-se mais de quatro séculos para a arte/educação estabelecer seus paradigmas. Desde o nascimento da Modernidade até hoje, então a presente situação da educação da cultura visual é apenas um começo para examinar seus valores, opiniões, entendimentos, práticas.

\section{Atrelamentos: questões de gênero, sexualidade, moralidade, currículo e arte/educação}

A moralidade cultural é um assunto muito importante para a teoria e a prática da arte/educação. Sem dúvidas, a análise de representações de gênero e sexualidade normativas e não-normativas (queer), projeta reflexões sobre o impacto teórico e prático que a compreensão destes sistemas visuais e seus discursos teriam na educação da cultura visual. É importante explorar a questão da moralidade dentro da perspectiva do deslocamento histórico da arte/educação para a educação da cultura visual, observando como elas ponderam, compreendem 
e reconhecem a construção, manutenção, circulação e inclusão de gêneros e sexualidades.

Antes que prossiga com esse assunto, é fundamental que, neste momento, esclareça o uso dos termos "queer" e "teoria queer". Utilizo o adjetivo "queer" para friccionar e, principalmente, situar transversalmente várias categorias e classificações convencionais, normativas das representações de gênero e sexualidade. Já uso "teoria queer" ocupando, dentre outras coisas, de teorias sobre a visibilidade da construção, estabelecimento e circulação discursiva do sexo e gênero. Reiteradamente, uso os termos "visível" e "invisível" como indícios de suas representações políticas e diferentes possibilidades interpretativas. Ao sugerir que sexualidade, sexo e gênero são construções sociais, portanto, mutáveis e deslocáveis, nem sempre simetricamente alinhadas, a teoria queer abre novas formas de aproximação com a sexualidade e o gênero que desarticulam conceitos de normalidade. Ao expor as relações entre sexualidade, sexo e gênero como oscilantes, a teoria queer envolve a sexualidade e gênero como efeito da memória social e individual; e abre-se para possibilidades de articulações entre definições e conceitos, principalmente, da lingüística, sociologia, antropologia, biologia, filosofia, estudos culturais e a psicologia. Portanto, a teoria queer, como um corpo teórico, é utilizada neste trabalho como um dos possíveis suportes metodológicos da educação da cultura visual porque permite fluxos transdisciplinares de espaços e lugares.

Quando a referência é "moralidade", pode-se afirmar com certeza que, atualmente, no começo do século XXI, muitos arte/educadores ainda criam, aplicam e vivem currículos de arte/educação fundamentados em procedimentos e práticas que retrocedem ao século XIX e, além disso, aderem-se a visões anacrônicas do que é moralmente aceito na arte e na arte/educação. No sistema educacional formal do Ensino Básico ao Superior, há uma insuficiência de discussões formais sobre sexo, gênero, identidade de gênero e sexual e sexualidade, excetuando quando esses temas são monopolizados pelos discursos morais, religiosos e médicos do currículo. Isto é absolutamente chocante, dada a ênfase à sexualidade, imagens de gênero e 
a auto-exploração nas representações visuais contemporâneas existentes no cotidiano.

Entretanto, da fundação da arte/educação na América do Norte, em universidades americanas no começo do século XIX e durante o século passado, a arte/educação foi percebida, consistentemente, como uma prática para disseminar a moralidade; e inicialmente o desenho, particularmente, foi percebido como a sua força moral, devido à influência do Romantismo (EFLAND, 1990, pp 69-73). Efland também destaca que a pedagogia da arte da auto-expressão do começo do século $X X$, que ainda prospera nas práticas atuais da arte/educação contemporânea, fez os arte/educadores perderem o contato com a maioria das questões sociais da vida diária comunitária. Desse modo, os arte/educadores perderam a perspectiva de relacionar as transformações morais da sociedade com os artefatos culturais produzidos por seus sujeitos.

Logo em seguida, porém, "a corrente reconstrucionista", informada pelas idéias de Dewey, sugeria que a arte era mais do que a experiência e conhecimento individuais. Era também um meio para mudar a sociedade e a vida individual, produzindo possibilidades embriônicas para reconectar arte e sociedade. Jagodzinski (1997a) nos informa que a sanção dada pela arte/ educação americana ao sentido da visão como o espaço privilegiado para ensinar e aprender, começou somente nos anos Vinte, influenciada pelas origens tecnológicas e institucionais da televisão e do estabelecimento do cinema como meio de massa. Essa tentativa de trazer a visualidade para a arte/educação indicou inicialmente um distanciamento do desenho mecânico que tanto influenciava a arte/educação até então. Mas, o que parecia ser um empreendimento crítico da arte e do cotidiano, tomou uma direção diferente porque arte/educadores rejeitaram a "cultura visual" e "voltaram-se para o cânon da arte ocidental, que só valoriza tradicionalmente as grandes obras de arte, de modo que a moral pudesse ser ensinada nas escolas" (1997, p. 17).

Mais recentemente, concepções de Arte Educação Multicultural, como uma fundação para o desenvolvimento de currículos, vêm nos incentivando a reavaliar noções de moralidade, 
excelência, racismo e histórias da pedagogia social reconstrucionista. Como sabemos, tem havido um crescente reconhecimento por parte de arte/educadores interessados em teoria social, como Michael J. Emme, Graeme Chalmers, Patricia Stuhr, Ed Check, Dipti Desai, Jan Jagodzinsk, Elizabeth Garber, Doug Blandy, Kristin Congdon, Rita L. Irwin, Karen Kiefer-Boyd, Laurie Hicks entre outros, de que os discursos sociais a respeito da sexualidade, gênero, raça, classe, idade, inaptidões e culturas aborígines são razoavelmente imperceptíveis na arte/educação porque os sistemas culturais, políticos e econômicos que sustentam a arte/educação valorizam algumas imagens, conceitos e teorias em detrimento de outras. Diante desta situação, desde os anos Noventa, um grande número desses arte/educadores entenderam também que a inclusão da diversidade cultural era extremamente relevante para um deslocamento epistemológico da arte/educação para a educação da cultura visual. Desde então, uma reconceitualização da arte/educação tem sido buscada formalmente para acolher todos os outros invisíveis do currículo. Chalmers (1996) foi uma das vozes iniciais a chamar atenção para esses assuntos, como ele ilustra:

O currículo necessita ser reformulado de modo que enfatize a unidade dentro da nossa diversidade, mostrando que todos os seres humanos fazem e usam a arte por razões similares. Mas, infelizmente, há questões como as do racismo e o sexismo que absolutamente nos exigem a implementação de abordagens em que o fazer e aprender arte transformem-se em maneiras de participar na reconstrução social" (p.45).

Isto também é bem ilustrado pelo trabalho de Honeychurch e Check (CHECK, 1992; HONEYCHURCH, 1995; CHECK, 1996; HONEYCHURCH, 1998) que, até 2006, juntamente com o meu trabalho (DIAS, 2006), produziram as únicas três teses na América do Norte que articulavam relações da arte/educação com gêneros e sexualidades e, no caso específico, com a teoria queer. Honeychurch (1998) destaca que na metade dos anos Noventa a sexualidade era invisível, excluída das discussões de diferença na arte/educação. Não havia nenhum estudo em profundidade que abordasse a representação de gays ou lésbicas nos cursos e programas de artes visuais. Além disso, havia 
uma falta de conteúdo, compreensão e conhecimento sobre as questões de identidades sexuais e de gênero dentro dos currículos de arte/educação. Havia, até mesmo, uma forte reação negativa por parte dos arte/educadores e administradores educacionais às experiências de aproximação com esses assuntos.

Acredito que, desde então, nada parece ter mudado muito, a menos que nós consideremos algumas atividades demasiadamente modestas que vêm ocorrendo em projetos dispersos pelo mundo, até mesmo no Brasil. Check (1992) informa que apesar dessas histórias de invisibilidade, que se tornam cada vez mais aparentes ultimamente, a heterossexualidade remanesce a norma privilegiada na cultura ocidental e é representada como naturalizada. Conseqüentemente os sujeitos, práticas e identidades sexuais que fogem a esta naturalização tornam-se, no melhor dos casos, tolerados nas escolas, e tem até a função "educadora" de reforçar a heteronormatividade por oposição binária. Contudo, os métodos para negociar as sexualidades e gêneros queer (desviantes e estranhas à norma) na teoria e na prática da arte/educação, são rejeitados. Como Check explica:

Os campos da arte e da arte/educação negam e perpetuam os preconceitos da heterossexualidade. A idealização do heterossexual na sociedade e na arte perpetua valores e normas específicas e permitem uma dominação ideológica de grupos que discriminam ativamente àqueles com menos poder. Por exemplo, os historiadores de arte, os arte/educadores e os críticos da arte representamse como responsáveis em conduzir um estudo da arte que seja objetivo, sexualmente indiferenciado e política e economicamente desinteressado (1992, p. 99).

Além disso, Check afirma de um lado que as salas de arte legitimam as "autoridades e os preconceitos da cultura heterossexual, branca, masculina" (1992, p. 99), e do outro, que é por meio da utilização de um discurso estabelecido e disfarçado de "boa" arte/educação (significando aqui: práticas razoáveis, aceitáveis, decentes, respeitáveis, excelentes, de primeira classe, civilizadas, adequadas e normais), por professores acríticos a seus contextos e indicadores sociais, que as escolas mantêm as verdades, os privilégios e posturas universais do patriarcalis- 
mo e do sexismo. Mais importantes ainda: são as suas observações de que, se em conseqüência do impacto do gênero e a sexualidade nas questões das representações visuais, arte/educadores do Ensino Superior cada vez mais incluem e reconhecem os artistas cujos trabalhos foram anteriormente negligenciados pela história e currículo. Isto não significa que os assuntos de sexualidades e gêneros queer, incluindo questões de identidade e voz, subjetividade, poder, local/global, controle, imitação, performance, espetáculo e representação, foram instituídos no currículo, ou pelo menos, foram capazes de deslocar a normatividade da arte/educação na academia ou em outros lugares. Check finaliza que esses processos não ocorrem porque faltam dados ou informações na academia para avaliar o impacto da inclusão destas representações em todos os níveis escolares, nos parâmetros curriculares e em políticas educacionais.

Essa indiferença às representações queer de gênero e sexo é peculiar às práticas de pesquisa e ensino e também está presente na teorização do campo. Por exemplo, o Handbook of Research and Policy in Art Education (EISNER; DAY, 2004) não menciona as palavras "sexualidade" e "sexual" em todo o seu texto. Os termos e sentenças mais próximos que aparecem no manual são "sexismo" e "obras de arte com forte teor sexual", que são colocados no contexto da interdição, da censura e da proibição de imagens "sexualmente perigosas e violentas" nos museus (LANKFORD; SCHEFFER, 2004) e ao condenar o sexismo na escola de arte no Ensino Fundamental (MATHEWS, 2004). Em um manual com quase novecentas páginas, esta "ausência" é uma corroboração concreta da invisibilidade da sexualidade e do gênero na teoria da arte/educação. Mathews também afirma que, antes de conduzir qualquer análise em assuntos da arte/educação, é imperativo reconhecer que este campo é engendrado do feminino. Ele é um campo em que as mulheres são as investigadoras dominantes e que falham ao não reconhecerem que, no contexto absoluto da arte/educação, ela é uma instituição "projetada por mulheres, implementada por mulheres e para mulheres" (2004, p. 285). Assim, de acordo com Mathews, o imaginário construído de uma suposta dominação masculina no campo não parece habitar o corpo 
masculino. O falo, neste caso, está com as mulheres.

Não obstante a estrutura de poder, a censura tem uma história longa na arte/educação. As instituições da arte/educação escondem, estrategicamente, os gêneros, mas invariavelmente, silenciam a sexualidade. A arte/educação permeada pela censura, agora e num passado próximo, exclui as representações de gêneros que incomodam as regras da normalidade, assim como aquelas que mostram preferências sexuais diferentes.

Emeril chama atenção ao fato que muitas obras de arte contemporâneas e práticas de arte são "violentas, sexualmente explícitas, repugnantes e psicologicamente perturbadoras" e logo, possivelmente, desagradável aos jovens (2002, p. 5). Ela concorda que os arte/educadores, ao incluir trabalhos "polêmicos" no currículo, correm o risco de afligir pais, diretores e a comunidade. Ademais, arte/educadores temem que os estudantes copiem as controvertidas imagens na comunidade. Mas, como os arte/educadores podem avaliar e verificar quando, como e por que uma obra de arte é obscena, ou controversa? Como a censura é vivida nas práticas da arte/educação? De que maneira é produzida e disseminada? Como os arte/educadores podem ambicionar ter o poder sobre o que outros seres humanos devem ver ou não? É o papel dos arte/educadores promover esta repressão?

No curso destes últimos pensamentos, eu me lembrei de uma noção popular em educação que afirma que os estudantes estão sempre em necessidade de proteção porque formam uma audiência vulnerável. Porém, Barker sugere que o foco em crianças como um grupo carente e vulnerável de audiência é "uma tática emocional para ganhar o apoio para o aumento da censura" (apud BROOKER; JERMYN, 2003, p. 52). Este conceito, limitado, de estudantes como jovens dependentes, passivos e vulneráveis aos efeitos prejudiciais da cultura visual não reconhece o poder da interação entre espectadores e os objetos que estão sendo vistos; e não admite o poder do imaginário de nossas vidas diárias em influenciar as noções de identidade, da consciência das questões sociais e do desenvolvimento cognitivo dos estudantes. Reconheço que mais pesquisas são necessárias para desconstruir estas práticas dominantes na 
arte/educação, pois arte/educadores raramente fazem estas perguntas, ao se depararem com obras de arte consideradas "controversas". A maioria evita trazê-las para a sala de aula e, assim, manda a arte para fora da escola e, possivelmente, das experiências iniciais de muitos estudantes. E é exatamente devido a estas constantes "supressões" que arte/educadores usam freqüentemente uma escala limitada de artistas extraídos somente de algumas localidades, períodos históricos, nacionalidades e empregam raramente outras artes, artistas e localidades epistemológicas possíveis.

Um outro fluxo de discussões ocorre quando as sexualidades invisíveis do corpo de estudantes e arte/educadores tornam-se aparentes na escola. Para explorar este assunto, destaco as reiteradas afirmações de Garber (2003) de que a iniqüidade de gênero e sexualidade remanesce um problema grave nas escolas. Garber revela que em alguns lugares, como as salas de aula, incentivam-se estudantes a falar sobre algumas características deles mesmos, mas não de outras. Isto é ainda mais árduo para os estudantes conectá-los a elementos de raça, sexualidade e classe e, particularmente, quando estão atreladas às de gênero (2003, p. 56). Curiosamente, este "sair do armário" dos arte/ educadores e dos seus relacionamentos com estudantes não é nem abordado pela literatura disponível na arte/educação.

Seguindo Garber, Lampela $(2001 ; 2005)$ comenta que estudantes e professores gays e lésbicas freqüentemente experimentam perseguições, intimidações e alienações. Constituindo a maioria em classes de arte/educação, os heterossexuais, na maior parte mulheres estudantes e professoras, estão mais interessadas na sexualidade discutida nos termos de seus relacionamentos homem/mulher, relegando todas as outras formas de relacionamento sexual às margens. Estes indivíduos discutem freqüentemente que aqueles relacionamentos queer são demasiadamente difíceis de compreender. De certa forma, o conservadorismo que existe de forma endêmica nas escolas intensifica ainda mais a censura.

Cosier e Sanders (2005) construindo em cima do trabalho de Garber, Desai, Honeychurch e Check têm defendido dentro da NAEA um pensamento crítico no qual todos os arte/educa- 
dores sejam incentivados a incluir grupos de diversidade sexual e racial, com o objetivo de articular suas histórias, existências e posições; erradicar as limitações que separam a arte da realidade social; reconsiderar o que está incluído ou não no currículo; abranger artistas queers, educadores e sexualidades gays e lésbicas; incluir interesses queer no currículo; reposicionar raça e sexualidade para além de suas zonas do conforto; reconceitualizar conexões entre o pensar global e local; questionar a representação de raça, sexualidade, gênero e classe; desvendar e divulgar práticas opressivas; dissolver as características que encobrem e silenciam os assuntos queer e aumentar a quantidade de parcerias e de programas institucionais que apóiam os estudos queer (p. 16).

Não obstante, apesar dos esforços de Lampela, Cosier e Sanders em preparar o terreno para uma educação da cultura visual inclusiva, eu considero que demasiada ênfase está sendo colocada em como incorporar, incluir e encaixar artistas no currículo que têm uma identidade fixa de gênero ou sexual como, por exemplo, gay e lésbica. Minha crítica é baseada na informação apresentada anteriormente de que a posição manifesta da educação da cultura visual arte é a de contemplar as noções "fluidas" de identidades e de práticas sexuais. O modelo atual está claro: paradoxalmente ao desejado pela educação da cultura visual, a inclusão de conceitos fixos de identidades de gênero e sexual, em vez de promover a diversidade, reafirma noções da normalização, da heteronormatividade. Ao valorizar essas novas identidades, práticas da arte/educação podem ser convertidas em lugares guetizados onde alguns poucos arte / educadores usam a arte de grupos minoritários para atender pequenos grupos de estudantes.

Minha posição aqui é tão política quanto cognitiva, uma vez que considero que o ponto mais crucial e o mais radical a ser incluído no currículo não é o fato de que artistas ou as artes são gays, lésbicas, transgêneras ou bissexuais, mas sim a abrangência das modalidades de interpretações, a leitura e as análises de gênero e representações sexuais, a reflexão da crise das subjetividades e a perspectiva da subalternidade. Não que eu seja contra a inclusão de qualquer forma da representação 
visual, mas se arte/educadores enfocarem a diversidade do gênero e das identidades sexuais tomando como exemplo discursos essencialistas, como dos estudos gays e lésbicos ou de partes do pensamento feminista, então também serão incapazes de interpretar a fluidez das relações sociais que as produzem. Eu acredito que a produção destas na invisibilidade no campo da arte/educação é uma parte inerente de sua construção histórica: nós necessitamos distinguir e considerar suas origens, experiências e práticas enquanto a criticamos. Na verdade, o movimento queer de constantemente desordenar identidades fixas é muito mais inclusivo de todos os gêneros e sexualidades e mais apropriado para a inclusão de estudos do gênero e sexualidade do que as sugestões resultantes dos estudos gays e lésbicos. Além disso, uma aproximação teórica queer ao campo da arte/educação acolhe todos os tipos de representação visual, mas ao mesmo tempo, desloca a prática educacional para longe de todos os conceitos fixos que ela possa carregar, como a própria sexualidade, gênero, raça, classe e assim por diante. Essa posição é mais coerente com a educação da cultura visual.

Check, Deniston e Desai (1997) insistem que a sexualidade, a classe e a raça, quando chegam a ser discutidas na arte/ educação o são, freqüentemente, em termos abstratos e que não representam experiências vividas. Desai indica que "o discurso multicultural da arte/educação remanesce surdamente silencioso sobre a diversidade sexual" (2003, p. 151). Como Desai descreve, a inclusão da sexualidade no currículo de artes sugere que a homossexualidade é a diferença preliminar em cima do que os arte/educadores têm focalizado. Essa posição, ela indica, ignora as conexões cruciais entre sexualidade e raça, etnicidade e gênero, entre outros, que os arte/educadores deveriam prestar atenção. Estes estudos devem ser relacionais. Apoiando-se neste argumento e esticando-o ainda mais e mais, Desai e outros arte/educadores (PURPEL, SHAPIRO et al., 1995; HORNE; LEWIS, 1996; JAGODZINSKI, 1997b; BROOKER; JERMYN, 2003) reafirmam a necessidade em colocar a sexualidade no núcleo comum de uma arte/educação multicultural, pois, de acordo com ela, a Arte Educação Multicultural até agora vem falhando em abordar eficientemente as questões 
da diversidade sexual.

Apoiando-se na teoria queer para refletir sobre o lugar que a diversidade sexual tem dentro da arte/educação multicultural, Desai (2003) indica que os assuntos da diversidade sexual são essenciais para a arte/educação, especialmente em um momento em que os discursos da diferença estão justamente se tornando institucionalizados, como por exemplo, a Arte Educação Multicultural. Além disso, ela também incentiva a busca de conceitos de cultura mais inclusivos das complexidades e extraordinárias questões da sociedade. Desai insiste que, se a arte/ educação exercitar uma compreensão de cultura associada ao poder, à produção, ao consumo e à apreciação de artefatos visuais da cultura, então ela será compreendida possivelmente dentro dos contextos históricos e sociais. Portanto, a arte/ educação não pode ignorar as significativas contribuições da teoria queer para mudar a maneira como nós pensamos sobre a cultura, como a descobrimos, limitamos, dispersamos e descentralizamos, como reconceitualizamos a sexualidade, desconectamos os gêneros e categorias sexuais e, principalmente, desconstruímos a heteronormatividade. Essa noção de cultura apresentada acima sugere um currículo interdisciplinar em arte/educação que não somente promova diversas leituras, mas incentive também a aprendizagem da leitura dos silêncios sociais produzidos pela escola, o entendimento dos efeitos daqueles silêncios e como nós passamos a compreendê-los em nossas vidas diárias. Finalmente, Desai conclui que se a arte/ educação quer ser levada a sério, então a maneira como lida com a diversidade sexual precisa ser examinada criticamente e o seu próprio discurso deve ser visto em termos de sua utilidade e da limitação de seu conceito da cultura.

\section{Fronteiras: considerações finais}

Iniciei este texto incitando arte/educadores a debater questões e representações de gênero e sexualidade na cultura visual para a construção de novas experiências curriculares em arte/educação. Nas minhas pesquisas atuais em teoria queer, 
cinema e ensino da cultura visual, ao colocar ênfase na análise do olhar queer, particularmente me interesso em investigar a relação que se cria entre o texto e o espectador como modelo interpretativo para uma subjetividade crítica e ativa na arte-educação. Além disso, busco compreender sistemas visuais de representações sexuais que têm um impacto teórico e prático para a arte-educação. Neste contexto, situado como um artista, educador e pesquisador, estou especialmente interessado no Ensino Superior de arte/educação e na possibilidade de deslocar seu foco do estudo da arte de elite para incorporar na discussão aspectos culturais do cotidiano, da cultura visual.

Busco neste texto preencher algumas lacunas na literatura crítica emergente na arte/educação contemporânea ao enfocar epistemologias de fronteiras e, desse modo, considerar interseções entre a pedagogia, artes visuais, cinema e estudos críticos como os culturais, queer e o pós-colonialismo. Tais estudos são raros no nosso campo. Nesta direção eu concordo plenamente com Desai que a arte/educação necessita estudar criticamente seu próprio discurso, adotar os conceitos da cultura que incluem uma análise contextualizada e constante das relações de poder e conhecimento e considerar a contribuição da teoria queer ao campo.

A cultura do cotidiano é um espaço que informa o espetáculo de gênero e sexualidade em nossa cultura e a juventude faz o uso da bricolagem no cotidiano como uma tentativa autônoma de construir e reapresentar sua percepção destas performances culturais. Portanto, uma prática de educação da cultura visual que destaque as representações visuais do cotidiano, de gênero e sexualidade, é uma experiência pedagógica significativa porque fornece uma miríade de oportunidades para cingir e adotar uma visão diversa da cultura, que não somente resiste acriticamente às representações visuais, mas incentiva a visão crítica como uma prática que desenvolva a imaginação, a consciência social e um sentido de justiça.

O cinema é um instrumento poderoso para compreender representações culturais porque provoca um incitamento de discursos, uma discussão social intensa de seus sentidos. Confesso que eu sempre estive atraído pelo trânsito das imagens criadas 
por diretores e pelas imagens visualizadas por espectadores, críticos, estudantes, estudiosos e público em geral. E neste texto, quando eu falo em cinema, eu estou particularmente interessado no ponto de encontro desses discursos e olhares em um mundo de imaginação, sentimentos, pensamentos que provocam posicionamentos com força pedagógica, particularmente a respeito das representações visuais explicitamente queers de gênero e sexualidade.

Durante meu estudos em torno das representações de gêneros e sexualidades queer, eu sou fortemente impelido a trabalhar com as noções de Mignolo (2000) de "epistemologia de fronteira", ou "epistemologia de bordas". Mignolo, partindo da posição latino americana, concebe a epistemologia de bordas como um argumento para a diversidade geopolítica que surge de uma perspectiva do subalterno, como uma forma de investigação viva, uma leitura que se dá pela parte externa, interna e por fora de todos os limites (2000, p. 40). A epistemologia de bordas aponta para um tipo diferente de poder, um poder múltiplo que é, em regra, transdisciplinar e significativamente aberto, uma vez que o seu objetivo é criar novas formas de análise e não somente contribuir aos sistemas já estabelecidos do pensamento. A noção da epistemologia de bordas de Mignolo, ou pensamento de bordas como ele prefere, é indubitavelmente uma reflexão que vem e pertence ao subalterno, mas não serve somente para o subalterno; a teorização do subalterno é para todos (MIGNOLO, 1998). A epistemologia de bordas ajuda a criar novos locais para se pensar dentro e entre discursos, disciplinas e diálogos. Assim, ela, como uma atividade de descolonização do conhecimento localizada no subalterno, incentiva o desenvolvimento de um "outro que pensa", deslocando as oposições binárias eu/outro e centro/ periferia, provocando um deslocamento de noções rígidas de conhecimento, visualidade, modos de ver, poder, identidade, subjetividade e agência.

Por fim, invoco a epistemologia de bordas porque considero que ela é uma das condições necessárias para que o deslocamento da arte/educação para a educação da cultura visual, que aceita a materialização de corpos teóricos, como a teoria 
queer como maneiras novas de saber, possa ajudar efetivamente a compreender e construir as representações culturais de gêneros e sexualidades na vida diária da sociedade.

\section{Notas}

1. Este texto é uma adaptação do capítulo três, interminglings, da tese de doutorado que defendi em abril de 2006 na University of British Columbia (UBC) Canadá, provisoriamente intitulada em português: Epistemologias de Fronteira: olhando para os queergenders de Almodóvar e sua implicação para a educação da cultura visual [Border Epistemologies: Looking at Almodóvar's Queergenders and its implications for Visual Culture Education]. Um extrato deste texto foi publicado em Dias, B (2005) Arte/Educação contemporânea: Consonâncias internacionais. Org. Ana Mae Barbosa. São Paulo Cortez, p. 277-291.

2. Delimito a minha descrição desta discussão à América do Norte. Posteriormente, desenvolverei um artigo sobre a situação no Brasil.

\section{Referências}

AGUIRRE, I. Beyond understanding of visual culture: A pragmatic approach to aesthetic education. JADE: The International Journal of Art and Design Education, v.23, n.3, p.256-269, 2004.

BARBOSA, A. M. A Imagem no ensino da arte. Porto Alegre: Perspectiva e Fundação IOCHPE, 1991. (Estudos)

John Dewey e o ensino de artes no Brasil. São Paulo: Cortez, 2001. 198 p.

BAUERLEIN, M. Symposium - Arts education and visual culture education: The burdens of visual culture. Arts Education Policy Reviews, v.106, n.1, p.5-12, 2004.

BOLIN, P. Artifacts spaces, and history: Art education and material culture studies. Arts and Learning Research, v.10, n.1, p.143-157, 1992.

BOLIN, P. E.; BLANDY, D. Beyond visual culture: Seven statements of support for material culture studies in art education. Studies in Art Education, v.44, n.3, p.246-263, 2003.

BROOKER, W.; JERMYN, D. The audience studies reader. London and New York: Routledgeed, 2003.

CHALMERS, F. G. Celebrating pluralism: Art, education, and cultural diver- 
sity. Los Angeles: The Getty Education Institute for the Arts, 1996.

Celebrating pluralism Six years later: Visual transculture/s. Education and critical multiculturalism. Studies in Art Education, v.43, n.4, p.293-306, 2002.

Visual culture education in the 1960s. Art Education, v.58, n.6, p.6-11, 2005.

CHAPMAN, L. H. Studies of the mass art. Studies in Art Education, v.44, n.3, p.230-245, 2003.

CHECK, E. Queers, Art and Education. In: M. Zummuellen. Working papers in art education. Iowa city, IA: University of lowa Press, 1992. Queers, art and Education, p.98-109.

My self-education as a gay artist. (Ph.D.). The University of Wisconsin - Madison, United States - Wisconsin, 1996.

CHECK, E. ; DENISTON, G. et al. Living the discourses. Journal of Social Theory in Art Education, v. 17, p.38-68, 1997.

COSIER, K. ; SANDERS, J. NAEA news: Lesbian, gay, bisexual, and transgender issues caucus. Reston: National Art Education Association, 2005.

DEBORD, G. The society of spectacle. New York: Zobe Books, 1995.

DESAI, D. Multicultural Art Education and the heterosexual imagination: A question of culture. Studies in Art Education, v.44, n.2, p.147-161, 2003.

Places to go: Challenges to multicultural art education in a global economy. Studies in Art Education, v.46, n.4, p.293-308, 2005.

DIAS, B. Border epistemologies: Looking at Almodóvar's queer genders and their implications for visual culture education. (Ph.D.). Curriculum Studies, University of British Columbia, Vancouver, 2006. 268 p.

DUNCUM, P. A review of proposals for studying the popular arts. Journal of the Institute of Art Education, v.11, n.2, p.7-16, 1987a.

What? even Dallas? Popular culture within the art curriculum. Studies in Art Education, v.29, n.1, p.7-16, $1987 \mathrm{~b}$.

Clearing the decks for dominant culture: Some first principles for a contemporary art education. Studies in Art Education, v.31, n.4, p.207-215, 1990.

Art education for new times. Studies in Art Education, v.38, n.2, p.69-79, 1997.

. Visual Culture Art Education: Why, What and How. Journal of Art \& Design Education, v.21, n.1, p.14-24, 2002a.

Clarifying visual culture art education. Art Education, v.55, n.3, p.6-11, 2002b.

Visual culture isn't just visual: Multiliteracy, multimodality and 
meaning. Studies in Art Education, v.45, n.3, p.252-265, 2004.

EFLAND, A. A history of art education: intellectual and social currents in the teaching of visual arts. New York: Teachers College Press, 1990.

EISNER, E. W. Educating artistic vision. New York: MacMillan, 1976.

The arts and the creation of minds. New Haven, CT, and London: Yale University Press, 2002.

EISNER, E. W. ; DAY, M. D. Handbook of research and policy in art education. Mahwah and London: Lawrence Erlbaum Associated, 2004.

EMERY, L. Censorship in contemporary art education. JADE: The International Journal of Art and Design Education, v.21, n.1, p.5-13, 2002.

EMME, M. J. Visuality in teaching and research: Activist art education. Studies in Art Education, v.43, n.1, p.57-74, 2001.

FREEDMAN, K. Interpreting gender and visual culture in art classrooms. Studies in Art Education, v.40, n.2, p.128-142, 1994.

Curriculum inside and outside of school representations of fine art and popular art. Journal of Art \& Design Education, v.16, n.20, p.157-170, 1997.

Social perspectives on art education in the U.S: Teaching visu-

al culture in a democracy. Studies in Art Education, v.41, n.4, p.314-329, 2001.

Teaching visual culture: Curriculum aesthetics and the social life of art. New York: Teachers College Press, 2003. (Advancing art education)

GARBER, E. Teaching about gender issues in art education classroom: Myra Sadker day. Studies in Art Education, v.45, n.1, p. 56-72, 2003.

HALL, S. Cultural representations and signifying practices. Thousands oaks, CA: Sage Publications, p. 400ed. 1997.

HEISE, D. Is visual culture becoming our canon of art? Art Education, v. 57, n. 5, p. 41-46, 2004.

HOBBS, J. In defense of a theory of art and art education. Studies in art education, v.34, n.2, p.102-113, 1993.

HONEYCHURCH, K. G. Extending the dialogues of diversity: Sexual objectivities and education in the visual arts. Studies in Art Education, v.36, n.4, p. 210-217, 1995.

Inside out/outside in - Sexual diversity: A comparative case study of two postsecondary visual art students. (PhD). Faculty of education, University of British Columbia, Vancouver, 1998. 200 p.

HORNE, P. ; LEWIS, R. Lesbian and gay sexualities and visual cultures. New York and London: Routledge, 1996. 
JAGODZINSKI, J. Postmodern dilemmas: Outrageous essays in art \& art education. New Jersey: Lawrence Erlbaum Associates Publishers. 1997a. 270 p. (Studies in curriculum theory) Pun(k) deconstruction: Experifigural writings in art \& art education. Mahwah, NJ and London: Lawrence Erlbaum Associates. 1997b.

KAMHI, M. M. Where is the art in today's art education? Aristos, 2002. Art succumbs to "visual culture": Aristos, 2003. Rescuing art from visual culture studies: Aristos,2004. Modernism, postmodernism, or neither? A fresh look at "Fine Art": Aristos, 2005.

KINDLER, A. M. Visual culture, visual brain and (art) education. Studies in Art Education, v.44, n.3, p.290-296, 2003.

KUHN, T. S. The structure of scientific revolutions. Chicago: The University of Chicago Press, 1970.

LAMPELA, L. Lesbian and gay artist in the curriculum: A survey of artist teachers' knowledge and attitudes. Studies in art education, v.42, n.2, p.146-162, 2001.

Writing effective lesson plans while utilizing the work of lesbian and gay artists. Art Education, v.58, n.2, p.33-39, 2005.

LANKFORD, E. L. ; SCHEFFER, K. Museum education and controversial art: Living on a fault line. In: E. W. Eisner and M. D. Day (Ed.). Handbook of research and policy in art education. Lawrence Erlbaum Associates: Mahwah and London, 2004. Museum education and controversial art: Living on a fault line, p.201-223

MATHEWS, J. The art of infancy. In: E. W. Eisner and M. D. Day (Ed.). Handbook of reseach and policy in art education. Mahwah, NJ and London: Lawrence Erlbaum Associates, 2004. The art of infancy, p.253-298.

MIGNOLO, W. Postoccidentalismo: El argumento desde América Latina. In: S. Castro-Gómez; E. Mendieta et al (Ed.). Teoras sin disciplina: Latinoamericanismo, poscolonialidad y globalizacin en debate: Retrieved 05 May, 2003, from http://ensayo.rom.uga.edu/critica/teoria/castro/, 1998. Postoccidentalismo: El argumento desde América Latina.

Local histories/Global designs: Coloniality, subaltern knowledges, and border thinking. New Jersey, NJ: Princeton University Press, 2000. (Princeton Studies in culture/power /history)

PAULY, N. Interpreting visual culture as cultural narratives in teacher education. Studies in Art Education, v.44, n.3, p.264-284, 2003.

PURPEL, D. E.; SHAPIRO, S. et al. Beyond liberation and excellence: Reconstructing the public discourses in education. Westport and London: Berging \& Garving, 1995. 
SILVERS, A. Pedagogy and polemics: Are art educators qualified to teach visual culture? Arts Education Policy Reviews, v.106, n.1, p. 19-23, 2004.

SMITH, P. J. Visual culture studies versus art education. Arts Education Policy Reviews, v.104, n.4, p.3-8, 2003.

SMITH, R. Excellence in art education: Ideas and initiatives. Reston: NAEA, 1988.

Building a sense of art in today's world. Studies in Art Education, v.33, n.2, p.71-85, 1992 a.

Problems for a philosophy of in art education. Studies in Art

Education, v.33, n.4, p.253-266, 1992 b.

STANKIEWICZ, M. A. Keynote addresses: First general session. National Art Education Association conference. Denver, CO, 2004.

SULLIVAN, G. Seeing visual culture. Studies in Art Education, v.44, n.3, p.195-196, 2003.

TAVIN, K. M. Wrestling with angels, searching for ghosts: Toward a critical pedagogy of visual culture. Studies in Art Education, v.44, n.3, p.197213, 2003.

TORRES, L. Blurring the boundaries at the NAEA: Aristos,1991.

Teaching the arts to children: Sitting on furniture and other

"Visual Arts" experiences: Aristos, 2004.

. Critiquing the critics: Art's porous borders: Aristos, 2005a.

The National Portrait Gallery captive to postmodernism: Aris-

tos, $2005 b$.

VAN CAMP, J. C. Visual culture and aesthetics: Everything old is new again. Or is it? Arts Education Policy Reviews, v.106, n.1, p.33-37, 2004.

\section{BELIDSON DIAS}

é Doutor em Estudos Curriculares em Arte Educação - Artes Visuais, pela University of British Columbia (2006), Canadá; Mestre em Pintura pela Manchester Metropolitan University (1992) e Chelsea School of Art \& Design (1993), Inglaterra; Licenciado em Educação Artística - Artes Plásticas (1989) pela Universidade de Brasília. É Professor Adjunto do Departamento de Artes Visuais da Universidade de Brasília e membro da CACS, INSEA, CSSE, NAEA, ABEH, ANPAP, ASAE e FAEB. 